Canadian

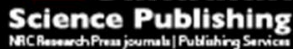

Canadian Geotechnical Journal Revue canadienne de géotechnique

Probabilistic Considerations for the Design of Deep Foundations Against Excessive Differential Settlement

\begin{tabular}{|r|l|}
\hline Journal: & Canadian Geotechnical Journal \\
\hline Manuscript ID & cgj-2015-0194.R2 \\
\hline Manuscript Type: & Article \\
\hline Date Submitted by the Author: & 28-Jan-2016 \\
\hline Complete List of Authors: & $\begin{array}{l}\text { Naghibi, Farzaneh; Dalhousie University, Engineering Mathematics } \\
\text { Fenton, Gordon; Dalhousie University, Dept. of Engineering Mathematics } \\
\text { Griffiths, D.; Colorado School of Mines, Civil and Environmental } \\
\text { Engineering }\end{array}$ \\
\hline Keyword: & $\begin{array}{l}\text { deep foundations, differential settlement, finite element method, design } \\
\text { pile length, reliability-based design }\end{array}$ \\
\hline &
\end{tabular}

SCHOLARONE ${ }^{m}$

Manuscripts 


\title{
Probabilistic Considerations for the Design of Deep Foundations Against
}

\section{Excessive Differential Settlement}

\author{
by Farzaneh Naghibi ${ }^{1}$, Gordon A. Fenton ${ }^{2}$, and D. V. Griffiths ${ }^{3,4}$
}

\begin{abstract}
Current foundation design practice for serviceability limit states involves proportioning the foundation to achieve an acceptably small probability that the foundation settlement exceeds some target maximum total settlement. However, it is usually differential settlement which leads to problems in the supported structure. The design question, then, is how should the target maximum total settlement of an individual foundation be selected so that differential settlement is not excessive? Evidently, if the target maximum total settlement is increased, the differential settlement between foundations will also tend to increase, so that there is a relationship between the two, although not necessarily a simple relationship. This paper investigates how the target maximum total settlement specified in the design of an individual foundation relates to the distribution of the differential settlement between two identical foundation elements, as a function of the ground statistics and the distance between the two foundations. A probabilistic theory is developed, and validated by simulation, which is used to prescribe target maximum settlements employed in the design process to avoid excessive differential settlements to some acceptable probability.
\end{abstract}

Keywords: foundation settlement, deep foundations, differential settlement, finite element method, design pile length

\footnotetext{
${ }^{1}$ Post-Doctoral Researcher, Department of Engineering Mathematics, Dalhousie University, Halifax, NS, Canada B3J2X4. farzaneh.naghibi@dal.ca

2 Professor, Department of Engineering Mathematics, Dalhousie University, Halifax, NS, Canada B3J 2X4. gordon.fenton@dal.ca (M.ASCE)

3 Professor, Department of Civil and Environmental Engineering, Colorado School of Mines, Golden, CO 80401, United States. D.V.Griffiths@mines.edu (F.ASCE)

4 Australian Research Council Centre of Excellence for Geotechnical Science and Engineering, University of Newcastle, Callaghan NSW 2308, Australia (F.ASCE)
} 


\section{Introduction}

Geotechnical foundation design is often governed by serviceability limit states (SLS), relating to settlement, rather than by ultimate limit states (ULS), which relate to safety. Most modern geotechnical design codes state that the serviceability limit state can be avoided by designing each foundation to settle by no more than a specified maximum tolerable settlement, $\delta_{\max }$. However, in the case of foundations, it is usually differential settlements which govern the serviceability of the supported structure. For example, if all of the foundations of a supported structure settle equally, but excessively, then the approaches to the structure may have to be modified, but the structure itself will not suffer from either a loss of serviceability nor from a loss of safety.

Almost certainly, individual foundations will not settle equally so that the differential settlement between foundations can lead to loss of serviceability and even catastrophic ultimate limit state failure in the supported structure. So the question is, how should differential settlement between foundations be properly accounted for in the foundation design process?

Although the settlement of deep foundation is not generally a concern if the piles are driven to refusal, settlement can become a design issue if no stiff substratum is encountered. As a result, this paper will concentrate attention on piles which are not end-bearing, that is on piles whose settlement resistance is derived from skin friction and/or adhesion with the surrounding soil.

Design code provisions should be kept as simple as possible, while still achieving a target reliability with respect to both serviceability and ultimate limit states. This means that design codes should retain their maximum total settlement requirements but the specified maximum settlement should be reviewed to reasonably confirm that differential settlements do not result in achieving either serviceability or ultimate limit states in the supported structure.

This paper investigates how the maximum settlement specified in a design code for an 
individual foundation relates to the distribution of the differential settlement between two foundations, as a function of the ground statistics and the distance between the two foundations. Figure 1 illustrates the settlement of two piles founded in a spatially variable ground. The paper will propose design code requirements on maximum settlements for individual foundations which aim to achieve target reliabilities against excessive differential settlements between pairs of foundations.

\section{Insert Figure 1 here.}

In this paper, the settlement of a pair of floating piles founded in a three-dimensional spatially random soil mass, each supporting a vertical load, $F_{T}$, is studied using the finite random element method (RFEM, Fenton and Griffiths 2008) employing a linearly elastic model. It is emphasized that this paper is about differential settlement, not total settlement. The mean total settlement entirely disappears from the predicted differential settlement, which depends only on the variance - the mean differential settlement is zero. What this implies is that the linearly elastic prediction used here for the mean settlement of each pile can be replaced by any more sophisticated nonlinear model without changing the results of this paper, so long as the more sophisticated model properly accounts for spatial variability in the ground. In turn, the latter means that it is essential to use a settlement model that properly accounts for spatial variability. While total settlement predictions may be better predicted using a non-linear model, with myriad parameters, the resulting model is of no use in this study unless the spatial statistics (mean, variance, and spatial correlation structure) can be estimated for the various parameters used in the more sophisticated model. However, it is hard enough to obtain the spatial statistics of a simple scalar random field, such as the elastic modulus field, without complicating things by trying to make use of spatially varying multi-variate, possibly cross-correlated, random processes that would be associated with a non-linear settlement model. In other words, the value of this paper would be muddied by trying to employ a model of unrealistic probabilistic complexity. The elastic 
model is perfectly adequate to capture the effects of spatial variability, especially since the mean settlement cancels out, so that errors in its estimation disappear.

With these thoughts in mind, a probabilistic model for differential settlement is presented, which is then validated via Monte Carlo simulation. The results are used to propose design provisions for piles to avoid excessive differentialsettlement at a target reliability level.

The paper is organized as follows: In Section 2, a finite element model is presented for a pair of floating piles founded in a three-dimensional spatially random soil mass, each supporting a vertical load. A theoretical approach to estimating the distribution of differential pile settlement is developed in Section 3, and the approach is validated via simulation in Section 4. Design code recommendations are then presented in Section 5, followed by Conclusions and proposed future work in Section 6.

\section{Finite Element Model}

The random settlement of a single pile, which was studied in depth by Naghibi et al. (2014b), is highly dependent on the random elastic modulus field of the surrounding soil, as well as on the pile geometry. In addition, when settlement of pile groups is of interest, mechanical interaction between the piles plays an important role in both total settlement and in differential settlement.

Consider two neighboring piles of identical geometry, supporting loads $F_{T_{1}}$ and $F_{T_{2}}$ and separated by distance $s$, as depicted in Figure 2. For generality in developing the theory, the pile loads will be considered to be random and possibly correlated (although in the validation and design sections, as well as the calibration of the mechanical interaction factor, it is assumed that $F_{T_{1}}=F_{T_{2}}=F_{T}=\mu_{T}$, i.e. non-random). If $\delta_{1}^{\prime}$ is the settlement of a vertically loaded individual pile without any neighboring piles, and $\delta_{1}$ is the overall settlement of the pile due to its loading and due to settlement of a neighbouring pile, $\delta_{2}^{\prime}$, then 


$$
\delta_{1}=\delta_{1}^{\prime}+\eta \delta_{2}^{\prime}
$$

where $\eta$ is the mechanical interaction factor between the two piles, which is a function of pile spacing and pile length. Rearranging eq. (1) and solving for $\eta$ gives

$$
\eta=\frac{\delta_{1}-\delta_{1}^{\prime}}{\delta_{2}^{\prime}}
$$

\section{Insert Figure 2 here.}

In order to predict $\eta$, predictions (or observations) of $\delta_{1}, \delta_{1}^{\prime}$, and $\delta_{2}^{\prime}$ are needed. In this paper, these quantities will be found using a linear elastic finite element model of the soil (Smith et al., 2014) with deterministic elastic modulus field ( $E=\mu_{E}$ everywhere, where $E$ is the elastic modulus, and $\mu_{E}$ is its mean). The piles are founded in a three-dimensional linear elastic soil mass modeled using a 50 by 30 by 30 finite element mesh, as illustrated in Figure 1. Eight-node brick elements are used with dimensions $0.3 \mathrm{~m}$ by $0.3 \mathrm{~m}$ in the $x, y$ (plan) and by $0.5 \mathrm{~m}$ in the $z$ (vertical) directions. Within the mesh, piles are modeled as columns of elements having depth $H$, and hence have a square crosssection with dimension $d=0.3 \mathrm{~m}$.

The prediction of $\eta$ is done for three pile lengths, $H=2,4$, and $8 \mathrm{~m}$, with separation distance, $s / d$, ranging between 2 and 30, where $s$ is the center-to-center pile spacing and $d$ is the pile diameter. For a particular choice of pile length, $H$, pile spacing $s$, applied load, $F_{T}=2.16 \mathrm{MN}$, pile to soil stiffness ratio $k=E_{p} / E_{s}=700$, soil elastic modulus $E=30 \mathrm{MPa}$, three finite element (FE) analyses are performed; one with pile 1 only, one with pile 2 only, and one with both pile 1 and pile

2 separated by distance $s$. The piles are placed at elements $(50-s / d) / 2$ and $(50+s / d) / 2$ 
numbered in the $x$ direction. For example, pile 1 only case involves the FE analysis of single pile settlement where pile 1 is placed at element $(50-s / d) / 2$, while the two pile case involves the FE analysis of two neighboring piles, pile 1 and pile 2 , placed at elements $(50-s / d) / 2$ and $(50+s / d) / 2$, respectively.

Note that the mechanical interaction, $\eta$, depends on pile spacing, $s$, and pile length, $H$, and is independent of $E$ or $F_{T}$. The dependence on Poisson's ratio, $v$, is negligible. The piles are placed at least 10 elements away from the boundaries of the FE model, which leads to relative pile settlement error of less than $10 \%$ (Naghibi et al., 2014a), so that the influence of boundary conditions on pile settlement is deemed to be negligible.

The resulting sequence of finite element analyses provided predicted values of $\eta$ for various $s / d$ and pile lengths, $H$, as shown in Figure 3. It is evident that $\eta$ increases with increasing pile length, $H$, and decreases with increasing $s / d$, as expected. For values of $H$ other than those specified in Figure 3, $\eta$ is predicted using linear interpolation for $2 \leq H \leq 8 \mathrm{~m}$ and linear extrapolation when $H$ falls outside this range.

\section{Insert Figure 3 here.}

\section{Probabilistic Settlement Model}

Attention is now turned to a probabilistic model of pile settlement, where the soil is assumed to be a spatially variable random field. To estimate the pile settlement, it is first assumed that the soil surrounding the pile is perfectly bonded to the pile shaft through friction and/or adhesion. Any displacement of the pile is thus associated with an equivalent displacement of the adjacent soil. Following the classic work of authors such as Poulos and Davis (1980), Randolph and Wroth (1978) 
and Vesic (1977), the soil is assumed to be linearly elastic, so that this displacement is resisted by a force which is proportional to the soil's elastic modulus and the magnitude of the displacement. Thus, the support provided by the soil to the pile depends on the elastic properties of the surrounding soil.

To design a pile against entering the serviceability limit state, that is, against entering a failure state where the pile's actual settlement exceeds a maximum tolerable settlement, a settlement prediction model is required. If the model is good, then it will provide a good estimate of the mean pile settlement and the in-situ actual pile settlement will be due to natural 'residual' soil variability around the predicted mean. The settlement prediction model is used to determine the pile design such that the predicted mean settlement is some fixed fraction (specified by the load and resistance factors) of the maximum tolerable settlement. If the settlement prediction model is poor, then it also contributes to the variability in the prediction of the actual settlement. This source of variability will be referred to here collectively as the 'degree of site and prediction model understanding', which includes (a) the degree of understanding of the ground properties and geotechnical properties throughout the site, and (b) the accuracy and degree of confidence about the numerical performance prediction model used to estimate the serviceability geotechnical resistances.

It is assumed in this paper that a sufficiently accurate settlement prediction model is used for the pile design, so that model error itself is attributable only to errors in the soil parameters used in the model, that is, to the degree of site understanding. This is probably a reasonable assumption, since if the (possibly non-linear) properties of the soil through which the pile passes, along with the nature of the interface between the pile and the soil, are all well known, then models exist which can provide very good estimates of the mean pile settlement. This paper is not attempting to provide an improved settlement prediction model. In fact a decision about the degree of site and prediction model understanding used in the pile design process is left to the designer. This paper concentrates on the 
residual settlement variability (around the mean) after the design has been performed. It is assumed that this variability arises from the spatial variability of the soil itself, along with uncertainty in the soil property estimates used in the prediction model.

It is recognized that pile settlement is almost certainly non-linear, and so the elastic modulus mean used in this simulation must be considered to be a secant modulus which approximates the curved nature of the actual pile load-settlement curve. However, the details of the mean settlement predictor used to design a pile and/or to estimate the distribution of differential pile settlement are not important to the subsequent probabilistic analysis (which is relative to the mean), and, of course, the reader is encouraged to use the best settlement prediction available to them. The linear model used in this paper is, however, the best currently available to predict the effects of spatial variability of the soil on the distributions of settlement and differential settlement.

The spatially varying elastic modulus field, which is assumed here to have a constant Poisson's ratio, $v$, may be characterized by an equivalent soil elastic modulus, $E_{g}$. The equivalent elastic modulus is a spatially uniform value that yields the same settlement as the pile experiences in the actual spatially varying soil (Fenton and Griffiths 2007). $E_{g}$ will be assumed here to be the geometric average of the spatially varying elastic modulus field, $E$, as will be discussed shortly. The elastic modulus is assumed to be lognormally distributed with mean $\mu_{E}$, standard deviation $\sigma_{E}$, and spatial correlation length, $\theta_{\ln E}$. The lognormal distribution is commonly used to represent non-negative soil properties and means that $\ln E$ is normally distributed with parameters $\mu_{\ln E}$ and $\sigma_{\ln E}$. The distribution parameters of $\ln E$ can be obtained from the mean and standard deviation of $E$ using the following transformations 


$$
\begin{aligned}
& \mu_{\ln E}=\ln \left(\mu_{E}\right)-\frac{1}{2} \sigma_{\ln E}^{2} \\
& \sigma_{\ln E}^{2}=\ln \left(1+v_{E}^{2}\right)
\end{aligned}
$$

where $v_{E}=\sigma_{E} / \mu_{E}$ is the coefficient of variation of $E$. If the soil's elastic modulus, $E$, is lognormally distributed, as assumed, then $E_{g}$ will also be lognormally distributed since geometric averages preserve the lognormal distribution (Fenton and Griffiths, 2008).

The correlation coefficient between the log elastic modulus at two points is defined by a correlation function, $\rho_{\ln E}(\tau)$, in which $\tau$ is the distance between the two points. In this study, a simple isotropic exponentially decaying (Markovian) correlation function will be employed, having the form

$$
\rho_{\ln E}(\tau)=\exp \left\{-\frac{2|\tau|}{\theta_{\ln E}}\right\}
$$

where $\tau$ is the distance between any two points in the field and $\theta_{\ln E}$ is the correlation length (Fenton and Griffiths 2008).

Since the soil is a spatially variable random field, the pile settlement will also be random. Assuming that the pile settlement is approximated lognormally distributed (as was shown to be reasonable by Naghibi et al. 2014b), then the task is to find the parameters of that distribution and the distribution of the resulting differential settlement. Assuming further that $\delta_{1}$ and $\delta_{2}$ are the total settlements of the two piles shown in Figures 1 and 2, then $\delta_{1}$ and $\delta_{2}$ are identically and lognormally distributed random variables.

The differential settlement between two piles is defined here to be $\Delta=\delta_{1}-\delta_{2}$. If the elastic 
modulus field is statistically stationary, as assumed here, then the mean differential settlement, $\mu_{\Delta}$, is zero. The mean absolute differential settlement can be approximated by (if $\Delta$ is approximately normally distributed)

$$
\mu_{|\Delta|} \square \sqrt{\frac{2}{\pi}} \sigma_{\Delta}
$$

which indicates that the mean of the absolute differential settlement is directly related to the standard deviation of $\Delta$, and hence related to the variability of the elastic moduli surrounding the piles. The approximation in eq. (5) is exact if $\Delta$ is normally distributed (Papoulis, 1991), and, as will be shown shortly, this approximation is in reasonable agreement with simulation based results.

Investigations by Fenton and Griffiths (2002) suggest that the equivalent elastic modulus as seen by a shallow foundation is a geometric average of the soil's elastic modulus under the foundation. Naghibi et al. (2014b) similarly assumes that the equivalent elastic modulus, $E_{g}$, as seen by a pile is a geometric average of the soil's elastic modulus over some volume, $V_{f}$, surrounding the pile

$$
E_{g}=\exp \left\{\frac{1}{V_{f}} \int_{V_{f}} \ln E(\underset{\sim}{x}) d \underset{\sim}{x}\right\}=\exp \left\{\frac{1}{B^{2} C} \int_{0}^{B} \int_{0}^{B} \int_{0}^{C} \ln E(x, y, z) d z d y d x\right\}
$$

where $E(\underset{\sim}{x})=E(x, y, z)$ is the elastic modulus of the soil at spatial position $(x, y, z)$. The pile is centered on the volume $V_{f}=B \times B \times C$ where $C$ is measured in the vertical $(z)$ direction.

The settlement of a single pile can then be expressed as

$$
\delta_{i}^{\prime}=\delta_{\operatorname{det}}\left(\frac{\mu_{E}}{E_{g}}\right)\left(\frac{F_{T_{i}}}{\mu_{T}}\right)
$$

where the subscript $i$ is either 1 or 2 , and $\delta_{\text {det }}$ is the deterministic settlement of a single pile obtained from a single finite element analysis of the problem using $F_{T_{i}}=\mu_{T}$ and $E=\mu_{E}$ everywhere. 
Substituting eq. (7) into eq. (1) leads to pile settlements, $\delta_{1}$ and $\delta_{2}$, as follows

$$
\begin{aligned}
& \delta_{1}=\delta_{\text {det }}\left(\frac{\mu_{E}}{\mu_{T}}\right)\left(\frac{F_{T_{1}}}{E_{g_{1}}}+\frac{\eta F_{T_{2}}}{E_{g_{2}}}\right) \\
& \delta_{2}=\delta_{\operatorname{det}}\left(\frac{\mu_{E}}{\mu_{T}}\right)\left(\frac{F_{T_{2}}}{E_{g_{2}}}+\frac{\eta F_{T_{1}}}{E_{g_{1}}}\right)
\end{aligned}
$$

The differential settlement, $\Delta=\delta_{1}-\delta_{2}$, between two piles becomes

$$
\Delta=\delta_{\text {det }}(1-\eta)\left(\frac{\mu_{E}}{\mu_{T}}\right)\left(\frac{F_{T_{1}}}{E_{g_{1}}}-\frac{F_{T_{2}}}{E_{g_{2}}}\right)
$$

The variance of $\Delta$ is therefore

$$
\sigma_{\Delta}^{2}=\delta_{\text {det }}^{2}(1-\eta)^{2}\left(\frac{\mu_{E}}{\mu_{T}}\right)^{2} \operatorname{Var}\left[\frac{F_{T_{1}}}{E_{g_{1}}}-\frac{F_{T_{2}}}{E_{g_{2}}}\right]
$$

where

$$
\operatorname{Var}\left[\frac{F_{T_{1}}}{E_{g_{1}}}-\frac{F_{T_{2}}}{E_{g_{2}}}\right]=\operatorname{Var}\left[\frac{F_{T_{1}}}{E_{g_{1}}}\right]+\operatorname{Var}\left[\frac{F_{T_{2}}}{E_{g_{2}}}\right]-2 \operatorname{Cov}\left[\frac{F_{T_{1}}}{E_{g_{1}}}, \frac{F_{T_{2}}}{E_{g_{2}}}\right]
$$

Now if $X_{i}=F_{T_{i}} / E_{g_{i}}, i=1,2$, and $F_{T_{i}}$ and $E_{g_{i}}$ are lognormally distributed, then $X_{i}$ is also lognormally distributed. In this case, $\ln X_{i}=\ln F_{T_{i}}-\ln E_{g_{i}}$ is normally distributed with parameters (Naghibi et al., 2014b)

$$
\begin{aligned}
\mu_{\ln X_{i}} & =\mu_{\ln F_{T}}-\mu_{\ln E_{g}}=\mu_{\ln F_{T}}-\mu_{\ln E} \\
& =\ln \left(\mu_{T}\right)-\frac{1}{2} \sigma_{\ln F_{T}}^{2}-\ln \left(\mu_{E}\right)+\frac{1}{2} \sigma_{\ln E}^{2} \\
\sigma_{\ln X_{i}}^{2} & =\sigma_{\ln F_{T}}^{2}+\sigma_{\ln E_{g}}^{2}=\sigma_{\ln F_{T}}^{2}+\sigma_{\ln E}^{2} \gamma_{f}
\end{aligned}
$$

assuming that $F_{T_{i}}$ and $E_{g_{i}}$ are independent, and where $\gamma_{f}$ is the variance reduction due to averaging $\ln E$ over the three-dimensional volume $V_{f}=B \times B \times C$ surrounding the piles. In 
detail,

$$
\gamma_{f}=\frac{1}{V_{f}^{2}} \int_{0}^{V_{f}} \int_{0}^{V_{f}} \rho_{\ln E}\left({\underset{\sim}{1}}_{1}-{\underset{\sim}{2}}_{2}\right) d{\underset{\sim}{1}}_{1} d{\underset{\sim}{\sim} 2}_{2}
$$

where $\underset{\sim}{x}$ and $\underset{\sim}{x}$ are two spatial positions within $V_{f}$. Note that $\gamma_{f}$ is essentially just the average correlation coefficient between all points within the volume $V_{f}$.

The distribution parameters of $X_{i}$ can be obtained from the mean and standard deviation of $\ln X_{i}$ using following transformations

$$
\begin{aligned}
& \mu_{X_{i}}=\exp \left\{\mu_{\ln X_{i}}+\frac{1}{2} \sigma_{\ln X_{i}}^{2}\right\} \\
& \sigma_{X_{i}}^{2}=\mu_{X_{i}}^{2}\left(e^{\sigma_{\ln X_{i}}^{2}}-1\right)
\end{aligned}
$$

Using eq.'s (12) in eq.'s (14) results in

$$
\begin{aligned}
\mu_{X_{i}} & =\mathrm{E}\left[\frac{F_{T_{i}}}{E_{g_{i}}}\right]=\exp \left\{\ln \left(\mu_{\mathrm{T}}\right)-\frac{1}{2} \sigma_{\ln F_{T}}^{2}-\ln \left(\mu_{E}\right)+\frac{1}{2} \sigma_{\ln E}^{2}+\frac{1}{2} \sigma_{\ln E}^{2} \gamma_{f}\right\} \\
& =\frac{\mu_{\mathrm{T}}}{\mu_{E}} \sqrt{\left(1+v_{E}^{2}\right)^{\gamma_{f}+1}} \\
\sigma_{X_{i}}^{2} & =\operatorname{Var}\left[\frac{F_{T_{i}}}{E_{g_{i}}}\right]=\left(\mu_{T}^{2}\left(1+v_{E}^{2}\right)^{\gamma_{f}+1} / \mu_{E}^{2}\right)\left(\exp \left\{\sigma_{\ln F_{T}}^{2}+\sigma_{\ln E}^{2} \gamma_{f}\right\}-1\right) \\
& =\frac{\mu_{T}^{2}}{\mu_{E}^{2}}\left(1+v_{E}^{2}\right)^{\gamma_{f}+1}\left(\left(1+v_{T}^{2}\right)\left(1+v_{E}^{2}\right)^{\gamma_{f}}-1\right)
\end{aligned}
$$

where $v_{E}=\sigma_{E} / \mu_{E}$ is the coefficient of variation of the elastic modulus field, $E$.

The covariance between the two lognormal random variables $X_{1}=F_{T_{1}} / E_{g_{1}}$ and $X_{2}=F_{T_{2}} / E_{g_{2}}$ can be computed as

$$
\operatorname{Cov}\left[X_{1}, X_{2}\right]=\operatorname{Cov}\left[\frac{F_{T_{1}}}{E_{g_{1}}}, \frac{F_{T_{2}}}{E_{g_{2}}}\right]=\sigma_{X_{i}}^{2} \rho_{X}
$$


where $\sigma_{X_{i}}^{2}$ is given by eq. (15), and the correlation coefficient, $\rho_{X}$, comes from the transformation (Fenton and Griffiths 2008)

$$
\rho_{X}=\frac{\exp \left\{\operatorname{Cov}\left[\ln X_{1}, \ln X_{2}\right]\right\}-1}{\exp \left\{\sigma_{\ln X_{i}}^{2}\right\}-1}
$$

and $\sigma_{\ln X_{i}}^{2}$ is defined by eq. (12). In addition

$$
\begin{aligned}
\operatorname{Cov}\left[\ln X_{1}, \ln X_{2}\right] & =\operatorname{Cov}\left[\ln F_{T_{1}}-\ln E_{g_{1}}, \ln F_{T_{2}}-\ln E_{g_{2}}\right] \\
& =\operatorname{Cov}\left[\ln F_{T_{1}}, \ln F_{T_{2}}\right]+\operatorname{Cov}\left[\ln E_{g_{1}}, \ln E_{g_{2}}\right] \\
& \square \sigma_{\ln F_{T}}^{2} \rho_{\ln F_{T}}+\sigma_{\ln E}^{2} \gamma_{f f}
\end{aligned}
$$

again assuming $F_{T}$ and $E_{g}$ are independent. The correlation $\rho_{\ln F_{T}}$ is given by

$$
\rho_{\ln F_{T}}=\frac{\ln \left(1+\rho_{F_{T}} v_{T}^{2}\right)}{\ln \left(1+v_{T}^{2}\right)}=\frac{\ln \left(1+\rho_{F_{T}} v_{T}^{2}\right)}{\sigma_{\ln F_{T}}^{2}}
$$

where $\rho_{F_{T}}$ is the correlation between loads $F_{T_{1}}$ and $F_{T_{2}}$. The term $\gamma_{f f}$ is the average correlation coefficient between two log-elastic modulus fields of sizes $V_{f}=B \times B \times C$ surrounding the two piles, which are separated by distance $s$ (see Figure 2 for $s$ ). In detail, $\gamma_{f f}$ is given by

$$
\gamma_{f f}=\frac{1}{V_{f}^{2}} \int_{0}^{V_{f}} \int_{0}^{V_{f}} \rho_{\ln E}\left(\sqrt{s^{2}+\left({\underset{\sim}{1}}_{1}-{\underset{\sim}{2}}_{2}\right)}\right)^{2} d{\underset{\sim}{1}}_{1} d{\underset{\sim}{\sim}}_{2}
$$

where $\rho_{\ln E}$ is given by eq. (4).

Employing eq's. (12) and (18) in eq. (17) leads to 


$$
\rho_{X}=\frac{\exp \left\{\sigma_{\ln F_{T}}^{2} \rho_{\ln F_{T}}+\sigma_{\ln E}^{2} \gamma_{f f}\right\}-1}{\exp \left\{\sigma_{\ln F_{T}}^{2}+\sigma_{\ln E}^{2} \gamma_{f}\right\}-1}=\frac{\left(1+\rho_{F_{T}} v_{T}^{2}\right)\left(1+v_{E}^{2}\right)^{\gamma_{f f}}-1}{\left(1+v_{T}^{2}\right)\left(1+v_{E}^{2}\right)^{\gamma_{f}}-1}
$$

and using eq.(15) and (21) in eq. (16) results in

$$
\operatorname{Cov}\left[X_{1}, X_{2}\right]=\frac{\mu_{T}^{2}}{\mu_{E}^{2}}\left(1+v_{E}^{2}\right)^{\gamma_{f}+1}\left(\left(1+\rho_{F_{T}} v_{T}^{2}\right)\left(1+v_{E}^{2}\right)^{\gamma_{f f}}-1\right)
$$

Finally substituting eq's. (15) and (22) into eq. (11) gives

$$
\operatorname{Var}\left[\frac{F_{T_{1}}}{E_{g_{1}}}-\frac{F_{T_{2}}}{E_{g_{2}}}\right]=2 \frac{\mu_{T}^{2}}{\mu_{E}^{2}}\left(1+v_{E}^{2}\right)^{\gamma_{f}+1}\left[\left(1+v_{T}^{2}\right)\left(1+v_{E}^{2}\right)^{\gamma_{f}}-\left(1+\rho_{F_{T}} v_{T}^{2}\right)\left(1+v_{E}^{2}\right)^{\gamma_{f f}}\right]
$$

from which the variance of differential settlement, $\sigma_{\Delta}^{2}$, becomes

$$
\sigma_{\Delta}^{2}=2 \delta_{\mathrm{det}}^{2}(1-\eta)^{2}\left(1+v_{E}^{2}\right)^{\gamma_{f}+1}\left[\left(1+v_{T}^{2}\right)\left(1+v_{E}^{2}\right)^{\gamma_{f}}-\left(1+\rho_{F_{T}} v_{T}^{2}\right)\left(1+v_{E}^{2}\right)^{\gamma_{f f}}\right]
$$

If $\rho_{F_{T}}=1$, so that the loads $F_{T_{1}}$ and $F_{T_{2}}$ are the same, then the above equation simplifies to,

$$
\sigma_{\Delta}^{2}=2 \delta_{\mathrm{det}}^{2}(1-\eta)^{2}\left(1+v_{E}^{2}\right)^{\gamma_{f}+1}\left(1+v_{T}^{2}\right)\left[\left(1+v_{E}^{2}\right)^{\gamma_{f}}-\left(1+v_{E}^{2}\right)^{\gamma_{f f}}\right]
$$


For $s \rightarrow \infty$, pile settlements $\delta_{1}$ and $\delta_{2}$ becomes independent, and hence both $\eta$ and $\gamma_{f f}$ in eq. (25) become zero. In this case, eq. (25) reduces to

$$
\sigma_{\Delta}^{2}=2 \delta_{\text {det }}^{2}\left(1+v_{E}^{2}\right)^{\gamma_{f}+1}\left(1+v_{T}^{2}\right)\left[\left(1+v_{E}^{2}\right)^{\gamma_{f}}-1\right]
$$

Assuming that the normal distribution is a reasonable approximate distribution of the differential settlement between two piles, then the probability that the differential settlement exceeds $\Delta_{\max }$ is

$$
\begin{aligned}
p_{f} & =\mathrm{P}\left[|\Delta|>\Delta_{\max }\right]=\mathrm{P}\left[\Delta<-\Delta_{\max } \cup \Delta>\Delta_{\text {max }}\right] \\
& =2 \mathrm{P}\left[\Delta<-\Delta_{\max }\right]=2 \Phi\left(\frac{\Delta_{\text {max }}-\mu_{\Delta}}{\sigma_{\Delta}}\right) \\
& =2 \Phi\left(\frac{\Delta_{\max }}{\sigma_{\Delta}}\right)=\Phi(-\beta)
\end{aligned}
$$

since $\mu_{\Delta}=0$, and where $\sigma_{\Delta}$ is calculated via eq. (24). The probability of failure, $p_{f}$, can also be expressed in terms of the reliability index, as shown in eq. (27), where $\Phi$ is the standard normal cumulative distribution function. That is, the reliability index corresponding to a particular value of $p_{f}$ can be obtained by inverting eq. (27), $\beta=-\Phi^{-1}\left(p_{f}\right)$

\section{Validation of Theory via Monte Carlo Simulation}

In this section, the predicted parameters of the distribution of differential settlement, $\Delta$, are compared to Monte Carlo simulation results in order to assess the accuracy of the theory developed in the previous section. The particular case considered in this validation study is detailed in Table 1 .

Insert Table 1 here.

Realizations of differential settlement of two piles are obtained using the random finite element method 
(RFEM) (Fenton and Griffiths 2008).

Three load cases $\left(F_{T}\right)$ are considered for this analysis, as listed in Table 1 and it is assumed that the pile loads are equal and non-random. For each load case, a design pile length is determined as follows to achieve a target maximum total settlement, $\delta_{\max }=0.025 \mathrm{~m}$ (Naghibi et al. 2014a)

$$
H=d\left[\left(\frac{1}{\left(\delta_{\max } \varphi_{g s} \mu_{E} d / F_{T}\right)-a_{0}}\right)^{1 / a_{2}}-a_{1}\right]
$$

where $\varphi_{g s}$ is the geotechnical resistance factor, accounting for uncertainty in geotechnical resistance. In this validation study, $\varphi_{g s}$ is taken to be 1.0. The pile to soil stiffness ratio is assumed to be $k=700$, from which $a_{0}=0.029, a_{1}=2.44, a_{2}=0.939$ are obtained using the following regression developed by Naghibi et al. (2014a)

$$
\begin{aligned}
& a_{0}=2069.4633(k+350)^{-1.6054} \\
& a_{1}=0.07+\left(0.2934 k^{0.3108}\right) \\
& a_{2}=0.6903+\left(8.2464 k^{-0.5268}\right)
\end{aligned}
$$

The resulting design pile lengths are $H=2,4$, and $8 \mathrm{~m}$ for the three load cases $F_{T}=1.46,2.16$, and 3.16 MN respectively.

The mechanical interaction factor, $\eta$, is obtained for each pile length (load case) and each pile spacing, $s$, listed in Table 2, using Figure 3. 
The soil volume surrounding the pile, $V_{f}=B \times B \times C$, for use in the geometric average given by eq. (6), was selected by trial and error (see Naghibi et al. 2014b) and the (approximately) best averaging volume was found to occur when $B=2 \mathrm{~m}$, and $C=2 H$. These choices led to the best agreement between theory and simulation with respect to settlement exceedance probabilities for a single pile.

Figures 4 and 5 illustrate the comparison between the theory and simulation-based estimates of $\mu_{|\Delta|}$ and $\sigma_{\Delta}$. The theoretical estimates were obtained using eq's. (5) and (24) for $\rho_{F_{T}}=1$ (identical loads), and $v_{T}=0$ (non-random load). Figure 4 demonstrates that the theory underestimates $\mu_{|\Delta|}$ when $\mu_{|\Delta|}$ is small. Although not seen in the figure, the underestimation occurs most strongly for longer piles and smaller values of $v_{E}$ and $\theta_{\ln E}$. The discrepancies between simulation and theory seen in Figures 4 and 5 arise mainly due to approximations made in the theory. For instance, the theory assumes that $\Delta$ is normally distributed - this is not a good assumption when $\mu_{|\Delta|}$ is small, which is where the errors become more pronounced. Note that the errors are actually quite small in absolute value and thus of not great importance. For example, when the simulated $\mu_{|\Delta|}$ is less than $0.5 \mathrm{~mm}$, the predicted $\mu_{|\Delta|}$ is often less than about $0.1 \mathrm{~mm}$. In either case, the differential settlement is negligible.

\section{Insert Figure 4 here.}

\section{Insert Figure 5 here.}

The probability that the differential settlement exceeds $\Delta_{\max }$, as predicted by eq. (27), is compared to simulation in Figure 6 for three possible maximum acceptable differential settlement to pile spacing ratio values, $\Delta_{\max } / s=1 / 200,1 / 500$, and $1 / 1000$. These serviceability gradient limitations are as specified in the Canadian Foundation Engineering Manual (CFEM) (Canadian Geotechnical Society2006) 


\section{Insert Figure 6 here.}

It is evident from Figure 6 that the theory sometimes significantly underestimates $\mathrm{P}\left[|\Delta|>\Delta_{\max }\right]$, which is unconservative. Although not shown in Figure 6, the disagreement is worst for smaller pile spacings, $s$. Note that the simulation involves fewer simplifications than does the theory, and so the simulation results are believed to be more accurate, as was also shown by Naghibi et al. (2014a).

It is believed that the discrepancy between theory and simulation in Figure 6 is due to the covariance between the piles being essentially overestimated in the theory by including both a statistical covariance component $\left(\gamma_{f f}\right)$ at the same time as a mechanical interaction term $(\eta)$. The overestimation in the 'equivalent' covariance between the piles reduces the theoretically predicted mean differential settlement, as seen in Figure 4, and thus significantly reduces the theoretical probability of excessive settlement, as seen in Figure 6. This discrepancy can be largely solved by introducing an empirical correction to the theory, which was found by trial-and-error. If the value of $\eta$ is replaced by $-0.5 \eta$ for short piles (e.g., $H<3 \mathrm{~m}$ ), by 0 for medium length piles (e.g., $3 \leq H \leq 6 \mathrm{~m}$ ), and by $0.5 \eta$ for longer piles (e.g., $H>6 \mathrm{~m}$ ), then the agreement between theoretical and simulated exceedance probabilities is significantly improved, as shown in Figure 7.

What this empirical adjustment is essentially doing is reducing the covariance between the piles the amount of covariance reduction is greatest for shorter piles, where most of the errors were seen, since the statistical covariance portion is relatively higher for shorter piles. The application of an empirical correction raises the question as to why the statistical covariance isn't reduced simply by reducing the volume $V_{f}=B \times B \times C$, rather than by reducing the mechanical component? The reason is that the choice in $V_{f}$ led to a good prediction of the distribution of the settlement of an individual pile, and so it was felt that its size was an appropriate measure of the zone around the pile influencing the 
total settlement. The problem really is that the mechanical interaction factor was determined from a deterministic (non-random elastic modulus field). The actual mechanical interaction factor in a spatially random elastic modulus field is unknown and not easy to specify probabilistically. Preliminary results using trials having identical random field realizations indicate that the random mechanical interaction factor is always lower than the deterministic mechanical interaction factor. However, it was felt that the determination of the distribution of the actual $\eta$ was beyond the scope of this paper, and perhaps not worth the effort, since the empirical adjustment suggested above seems to work so well.

With this empirical correction, the agreement between theory and simulation is considered very good. Thus, the theory is believed to be reliable enough to assist in design recommendations, as will be discussed shortly. In other words, the normal distribution, along with an empirically adjusted standard deviation, can be used as a reasonable approximation to the distribution of the differential settlement between two piles.

\section{Insert Figure 7 here.}

\section{Design Recommendations}

The objective of this section is to study how the design maximum tolerable total settlement, $\delta_{\max }$, for an individual pile, relates to the distribution of the differential settlement between two piles and, more specifically, to the maximum tolerable gradient, $\Delta_{\max } / s$.

The design $\delta_{\max }$ required to achieve a certain reliability against excessive differential settlement can be obtained by considering eq. (28), which is re-written here as, 


$$
H=d\left[\left(\frac{1}{\left(q \delta_{\max } \varphi_{g s}\right)-a_{0}}\right)^{1 / a_{2}}-a_{1}\right]
$$

in terms of $q$, having units of $m^{-1}$, which is defined by

$$
q=\mu_{E} d / \mu_{T}
$$

For given values of $\delta_{\max }, q$, and $d$, the design pile length $H$ can be determined from eq. (30) ( $k=E_{p} / \mu_{\mathrm{E}}=700$ is assumed here), which may be then used in eq.'s (13) and (20) to find $\gamma_{f}$ and $\gamma_{f f}$. The variance of $\Delta_{\max }$ is then obtained from eq. (25), as follows

$$
\sigma_{\Delta}^{2}=2 \delta_{\max }^{2}(1-\eta)^{2}\left(1+v_{E}^{2}\right)^{\gamma_{f}+1}\left(1+v_{T}^{2}\right)\left[\left(1+v_{E}^{2}\right)^{\gamma_{f}}-\left(1+v_{E}^{2}\right)^{\gamma_{f f}}\right]
$$

where $\delta_{\text {det }}$ has been replaced by the target design total settlement, $\delta_{\max }$.

Based on results presented in Naghibi et al. $(2014 \mathrm{~b})$, the correlation length, $\theta_{\ln E}$, leading to the highest mean differential settlement, is approximately equal to the distance between the two piles, $s$, and hence $\theta_{\ln E}=s$ is used for the estimation of $\sigma_{\Delta}$ in eq. (32). Once $\sigma_{\Delta}$ is known, the probability of excessive settlement can be determined by eq. (27). If the exceedance probability is larger than acceptable, then $\delta_{\max }$ must be reduced. This entire process can be repeated over a range of $s, q$, and $\delta_{\max }$ values to determine the design $\delta_{\max }$ value required to just achieve a target reliability, $\beta$.

The results of this iterative process are shown in Figure 8 using the parameters specified in Table 2. Note that the results are not sensitive to the choices in pile diameter, $d$, and the mean values, $\mu_{E}$ and $\mu_{T}$, since the design pile length takes all of these parameters into account - the actual settlement distribution will have mean which shifts accordingly with the assumed mean in the elastic 
modulus field and the load, as well as with pile diameter. The probability of excessive settlement thus depends only on the variability of the ground, and the probability of excessive differential settlement depends on $\delta_{\max }$, pile spacing, pile length, and correlation length.

Insert Table 2 here.

Figure 8 shows the required $\delta_{\max }$ as a function of $q$ for three maximum acceptable gradients, $\Delta_{\max } / s=1 / 200,1 / 500$, and 1/1000 (as specified by the CFEM, Canadian Geotechnical Society 2006), and for the various pile spacings, $s$, listed in Table 2 , to achieve a target reliability index $\beta=2.9$. This target reliability corresponds to a maximum acceptable failure probability of about $1 / 500$, which is what was assumed to be a typical maximum acceptable failure probability for SLS design in the Canadian Highway Bridge Design code (Canadian Standards Association 2014). The plots in Figure 8 can be used for design by drawing a vertical line at the specified $q$ value and then reading off the required $\delta_{\max }$ for a given pile spacing, $s$. For example, for applied load $\mu_{T}=1.0 \mathrm{MN}$, soil elastic modulus $\mu_{E}=20 \mathrm{MPa}$, and pile diameter $d=0.5 \mathrm{~m}, q=20 \times 0.5 / 1.0=10 \mathrm{~m}^{-1}$, and pile spacing $s=3 d=1.5 \mathrm{~m}, \delta_{\max }$ values of 19,12 , and $8 \mathrm{~mm}$ are recommended for the three acceptable gradients $\Delta_{\max } / s=1 / 200,1 / 500$, and $1 / 1000$, respectively.

\section{Insert Figure 8 here.}

Note that the stepped nature appearing in Figure 8 is due to the fact that discrete values of $\delta_{\max } / s$ are considered in the iterative process described above, rather than continuous. Thus, each discrete value of 
$\delta_{\max }$ applies to a continuous range in $q$.

The following observations can be made about the recommended $\delta_{\max }$ values in Figure 8;

a. By comparing plots $\mathrm{a}, \mathrm{b}$, and $\mathrm{c}$, in Figure 8 , it is evident that the design value of $\delta_{\max }$ increases with increasing $\Delta_{\max } / s$. This is as expected, since increasing $\Delta_{\max } / s$ results in a less restrictive SLS requirement.

b. Within each plot in Figure 8, it appears that the design value of $\delta_{\max }$ increases with increasing $s$, for fixed $\Delta_{\max } / s$. Although this observation seems to be counter to the first (as $s$ increases, it seems that $\Delta_{\max } / \mathrm{s}$ should decrease), it is important to remember that each plot in Figure 8 is for fixed $\Delta_{\max } / s$. Thus, an increase in $s$ is accompanied by a corresponding increase in $\Delta_{\max }$, so that all curves in Figure 8 have different $\Delta_{\max }$ values. The net result is that when $\Delta_{\max } / s$ is fixed, increasing $s$ results in increasing $\delta_{\max }$. This is also as expected, since for a fixed maximum gradient, increased spacing between foundations results in a less restrictive SLS requirement.

c. The design $\delta_{\max }$ decreases with increasing $q$. When $q$ is large, the elastic modulus is large and the load is small which leads to short piles. Short piles have larger variability in both their settlement and differential settlement. Thus, to achieve a certain reliability against excessive differential settlement, smaller values of $\delta_{\max }$ are required when $q$ is large. 


\section{Conclusions}

The differential settlement between two piles is studied and a theoretical model with an empirical adjustment is developed, which is then validated by simulation. The theoretical model can be used to estimate the probability of excessive differential settlement and hence to provide design recommendations. The relationship between the target maximum total settlement recommended in design codes and the distribution of the differential settlement between two piles was investigated and design recommendation were made on how to select the target maximum total settlement of an individual pile to avoid excessive differential settlement between a pair of piles.

The differential settlement model presented here is a function of the load and the ground stiffness distributions, along with the distance, correlation coefficient (in both loads and ground parameters), and mechanical interaction between the piles. The local averages used around the piles gave very good agreement between predicted and simulated exceedance probabilities for total settlement in the study by Naghibi et al. (2014b). However, using the same local averages in this paper overemphasized the correlation between piles. To compensate, an empirical adjustment factor was introduced. The resulting probabilistic model is quite general and the agreement between the model and differential settlement simulation results was deemed to be very good (see Fig. 7).

One of the goals of this paper was to produce design recommendations which allow the designed pile system to avoid excessive differential settlement between pairs of piles. Since the serviceability limit state design of foundations traditionally involves the specification of, and design against, a maximum total settlement, $\delta_{\max }$, it makes sense to continue that traditional design approach here. To this end, this paper provides maximum tolerable settlement values which correspond to a reliability index of at least $2.9\left(p_{f}=1 / 500\right)$ against excessive differential settlement. Note that the 
recommendations made here are based on variability in the ground and not on variability in the loads. That is, $v_{T}=0$ was used in the design recommendations and the loads applied to the two piles were assumed equal. The actual joint load distribution is dependent on the stiffness of the supported structure, amongst other things, and the stiffness of the supported structure also influences the maximum allowable differential settlement. To properly model the joint load distribution, and the maximum tolerable differential settlement, a model of the supported structure would be required, which was beyond the scope of this paper. The assumptions made here essentially correspond to that of a very stiff supported structure (e.g., a pile cap). If the structure is actually quite flexible, one would expect increased differential settlement, but at the same time one would expect additional tolerance for differential movement. It is felt that the results presented here are basically applicable regardless of the structural model. Nevertheless, research is ongoing into the effect that structural stiffness and load transfer mechanisms have on the SLS design of individual foundations against excessive differential movement.

\section{Acknowledgements}

The authors are thankful for the support provided by the Natural Sciences and Engineering Research Council of Canada and by a Special Research Project Grant from the Ministry of Transportation of Ontario(Canada). 


\section{References}

Canadian Geotechnical Society 2006. Canadian Foundation Engineering Manual, 4th Ed., Montreal, Quebec.

Canadian Standards Associations 2014. Canadian Highway Bridge Design Code, CAN/CSA-S6-14, Mississauga, Ontario.

Fenton, G.A. and Griffiths, D.V. 2002. "Probabilistic foundation settlement on spatially random soil," ASCE J. Geotech. Geoenv. Engrg., 128(5), 381-390.

Fenton, G.A. and Griffiths, D.V. 2007. "Reliability-based deep foundation design," Probabilistic Applications in Geotechnical Engineering, GSP No. 170, ASCE, Proc. Geo-Denver 2007 Symposium, Denver, Colorado, 1-12.

Fenton, G.A. and Griffiths, D.V. 2008. Risk Assessment in Geotechnical Engineering, John Wiley \& Sons, New York.

Naghibi, F., Fenton, G.A. and Griffiths, D.V. 2014 a. "Prediction of pile settlement in an elastic soil," Computers and Geotechnics, 60(2), 29-32.

Naghibi, F., Fenton, G.A. and Griffiths, D.V. 2014 b. "Serviceability limit state design of deep foundations," Geotechnique, 64(10), 787-799.

Papoulis, A. 1991. Probability, Random Variables, and Stochastic Processes, (3rd Ed.), McGraw- Hill, Inc., New York, New York.

Poulos, H.G. and Davis, E.H. 1980. Pile Foundation Analysis and Design, John Wiley \& Sons, New York.

Randolph, M.F. and Wroth, C. P. 1978. "Analysis of Deformation of Vertically Loaded Piles," $A S C E J$. Geotech. Geoenv. Engrg., 104(GT12), 1465-1488.

Smith, I.M., Griffiths, D.V. and Margetts, L. 2014. Programming the Finite Element Method, (5th Ed.), John Wiley \& Sons, New York, NY.

Vesic, A.S. 1977. Design of Pile Foundations, in National Cooperative Highway Research Program Synthesis of Practice No. 42, Transportation Research Board, Washington, D.C.. 


\section{List of Abbreviations and Symbols Used}

ULS Ultimate Limit State

SLS Serviceability Limit State

$a_{i} \quad$ settlement prediction parameter

$B \quad$ width of soil volume used in the geometric average around the pile

$\operatorname{Cov}[X, Y] \quad$ covariance between random variables $X$ and $Y$

$d \quad$ pile cross-sectional dimension $(=0.3 \mathrm{~m})$

E $\quad$ soil's elastic modulus (random)

$E_{g} \quad$ equivalent uniform soil elastic modulus that, if surrounding the pile, would yield the same settlement

$E_{p} \quad$ pile's elastic modulus

$E\left(\underset{\sim}{x_{i}}\right) \quad$ elastic modulus at the spatial location $\underset{\sim}{x_{i}}$

$\mathrm{E}[\cdot] \quad$ expectation operator

$F_{T} \quad$ true total load (random)

$H \quad$ designed pile length

$I_{p} \quad$ settlement influence factor

$k \quad$ pile to soil stiffness ratio $\left(=E_{p} / \mu_{\mathrm{E}}\right)$

$n_{\text {sim }} \quad$ number of simulations

$p \quad$ pile perimeter 


\begin{tabular}{|c|c|}
\hline$p_{f}$ & probability of failure $\left(=\mathrm{P}\left[|\Delta|>\Delta_{\max }\right]\right)$ \\
\hline $\mathrm{P}[\cdot]$ & probability operator \\
\hline$q$ & $=\mu_{E} d / \mu_{F}$ \\
\hline$S$ & centre-to-centre pilespacing \\
\hline$v_{E}$ & elastic modulus coefficient of variation $\left(=\sigma_{\mathrm{E}} / \mu_{\mathrm{E}}\right)$ \\
\hline$v_{T}$ & total load coefficient of variation $\left(=\sigma_{T} / \mu_{T}\right)$ \\
\hline$V_{f}$ & volume of geometric average around the pile $(=B \times B \times C)$ \\
\hline$X_{i}$ & ratio of load to elastic modulus geometric average $X=F_{T_{i}} / E_{g_{i}}$ \\
\hline$\underset{\sim}{x}$ & spatial coordinate, $(x, y, z)$ in $3-\mathrm{D}$ \\
\hline$\beta$ & reliability index $\left(=-\Phi^{-1}\left(p_{f}\right)\right)$ \\
\hline
\end{tabular}

$\gamma_{f} \quad$ variance function giving variance reduction due to averaging over the soil volume surrounding the pile

$\gamma_{f f} \quad$ average correlation coefficient between elastic modulus along two piles over the volume $V_{f}$

$\delta \quad$ overall settlement of pile due to its loading and due to the settlement of a neighboring pile $\delta^{\prime} \quad$ settlement of an individual pile

$\delta_{\text {det }} \quad$ pile settlement when $E=\mu_{E}$ everywhere

$\delta_{\max } \quad$ maximum acceptable settlement for an individual pile

$\Delta \quad$ differential settlement between two piles 


\begin{tabular}{|c|c|}
\hline$\Delta_{\max }$ & maximum acceptable differential settlement \\
\hline$\eta$ & mechanical interaction factor \\
\hline$\theta_{\ln E}$ & isotropic correlation length of the random log-elastic modulus field \\
\hline$\mu_{E}$ & mean elastic modulus \\
\hline$\mu_{\ln F_{T}}$ & mean of $\ln F_{T}$ \\
\hline$\mu_{\ln X_{i}}$ & mean of $\ln X_{i}$ \\
\hline$\mu_{X i}$ & mean of $X_{i}$ \\
\hline$\mu_{\Delta}$ & mean differential settlement \\
\hline$\mu_{|\Delta|}$ & mean absolute differential settlement \\
\hline$\mu_{T}$ & mean total load \\
\hline$v$ & Poisson's ratio \\
\hline$\rho_{F_{T}}$ & correlation coefficient between the loads applied to the two piles \\
\hline$\rho_{l n E}$ & correlation coefficientbetween $\ln E$ at two points \\
\hline$\rho_{\ln F}$ & correlation coefficient between the logarithm of the loads applied to the two piles \\
\hline$\rho_{X}$ & correlation coefficient between $X$ at the two piles $\left(X=F_{T} / E_{g}\right)$ \\
\hline$\sigma_{E}$ & standard deviation of elastic modulus \\
\hline$\sigma_{\ln E}$ & standard deviation of log-elastic modulus \\
\hline$\sigma_{\ln F_{T}}$ & standard deviation of the log-pile load \\
\hline$\sigma_{\Delta}$ & standard deviation of differential settlement \\
\hline$\tau$ & lag distance \\
\hline
\end{tabular}


$\varphi_{g s} \quad$ geotechnical resistance factor at SLS

$\Phi$

standard normal cumulative distribution function 


\section{Figure Captions}

Figure 1. Slice through a random finite element method (RFEM) mesh of a ground supporting two piles.

Figure 2. Relative location of two piles.

Figure 3. Plot of interaction factor, $\eta$, using FE model for $F_{T}=2.16 \mathrm{MN}, k=700, v=0.3$, and $E=30 \mathrm{MPa}$.

Figure 4. Predicted, obtained via eq. (5), versus simulated mean absolute differential settlement, $\mu_{|\Delta|}$, for all cases listed in Table 1.

Figure 5. Predicted, obtained via eq. (24), versus simulated standard deviation differential settlement, $\sigma_{\Delta}$, for all cases listed in Table 1 .

Figure 6. Predicted, via eq. (27), versus simulated $\mathrm{P}\left[|\Delta|>\Delta_{\max }\right]$ for all cases listed in Table 1 .

Figure 7. Predicted, obtained via eq. (27), versus simulated $\mathrm{P}\left[|\Delta|>\Delta_{\max }\right]$, adjusted by replacing $\eta$ with $-0.5 \eta$ for $H<3 \mathrm{~m}$, with zero for $3 \leq H \leq 6 \mathrm{~m}$, and with $0.5 \eta$ for $H>6 \mathrm{~m}$

Figure 8. Recommended design $\delta_{\max }$ versus $q$ for various pile spacings, $s$, and maximum acceptable gradient, $\Delta_{\max } / s=$ a) $1 / 200$, b) $1 / 500$, and c) $1 / 1000$. 


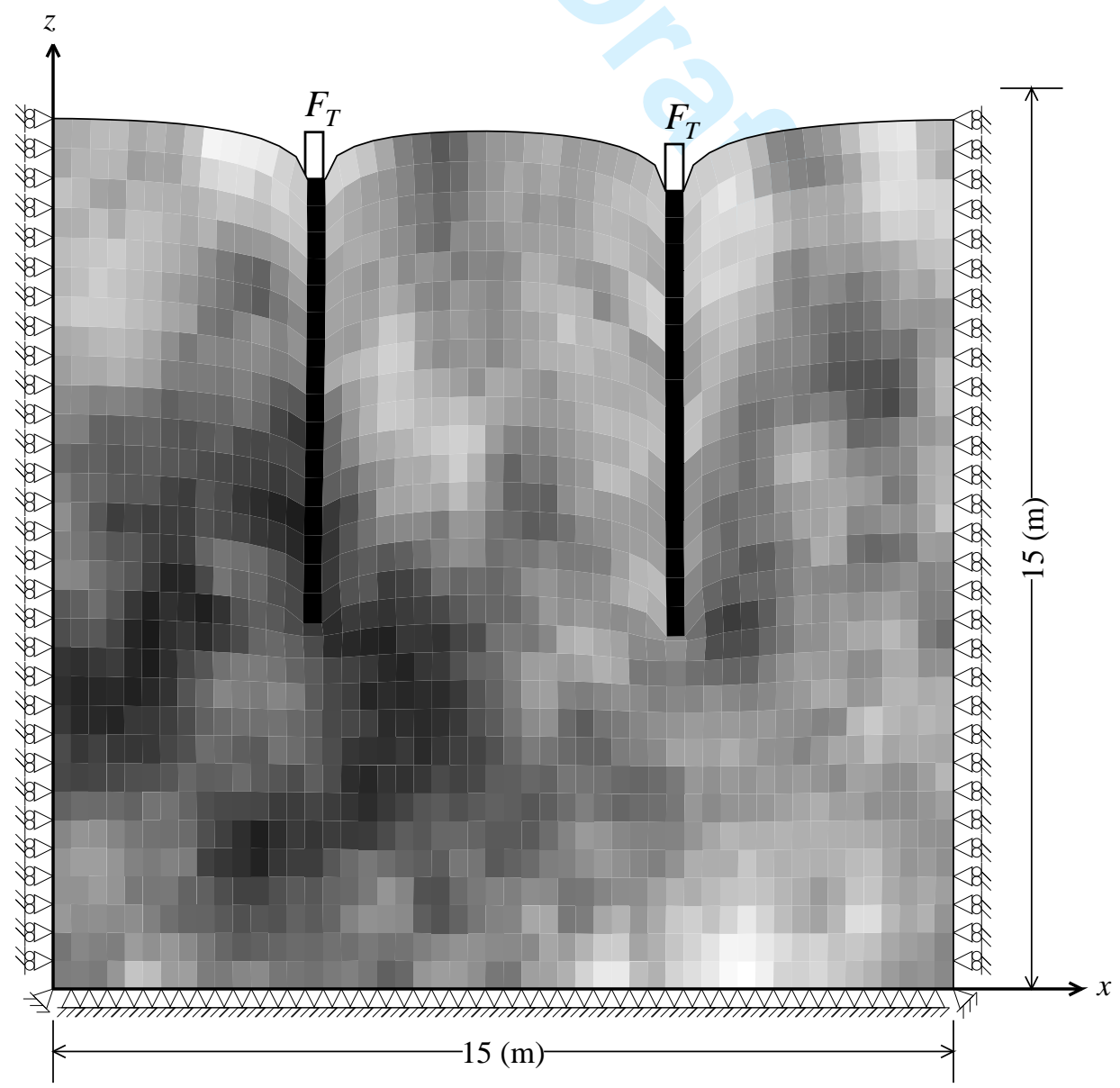

Figure 1. Slice through a random finite element method (RFEM) mesh of a ground supporting two piles. https://mc06.manuscriptcentral.com/cgj-pubs 


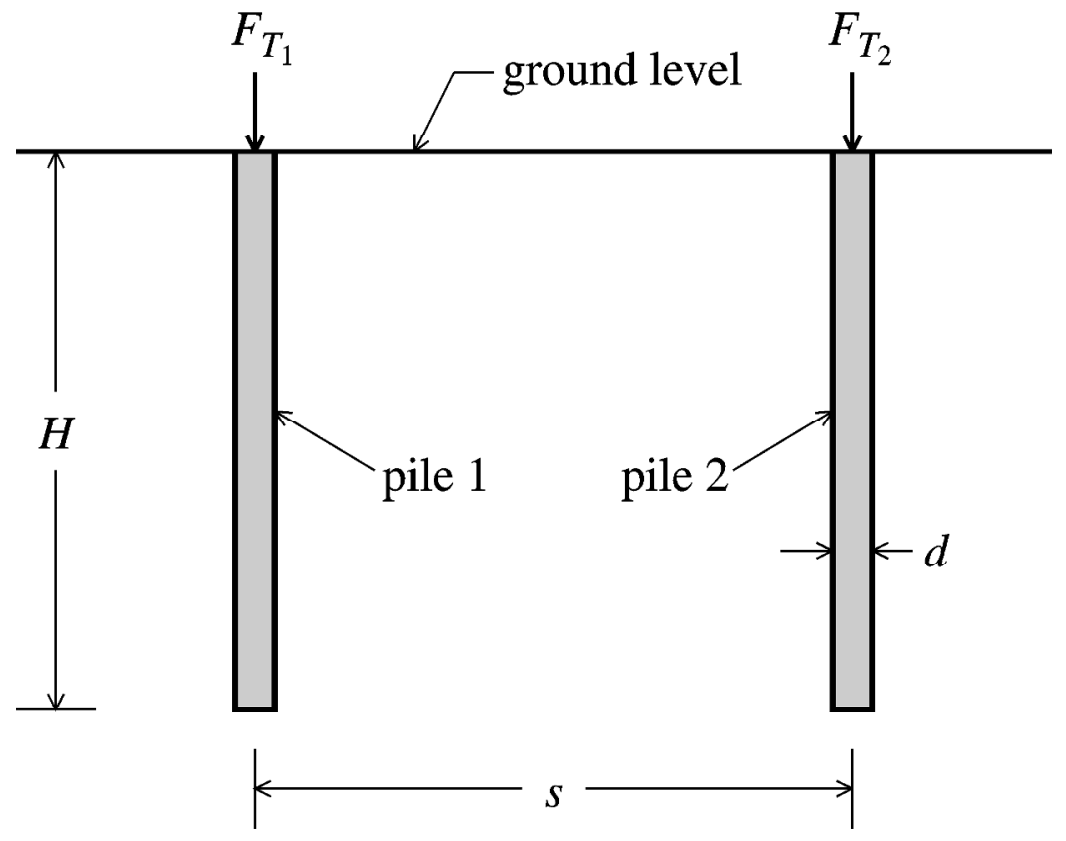

Figure 2. Relative location of two piles 


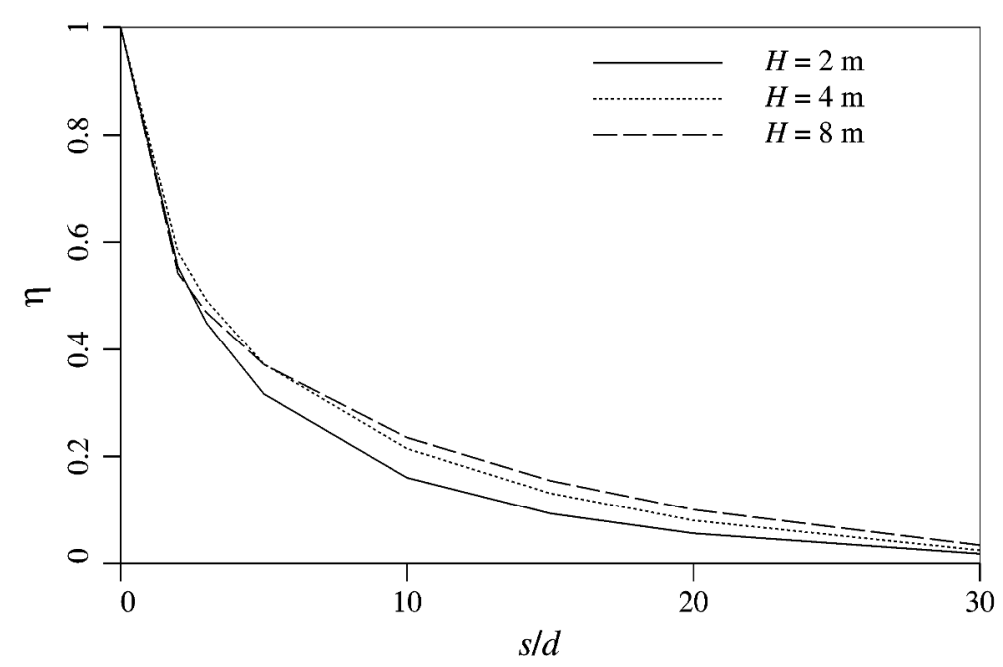

Figure 3. Plot of interaction factor, $\eta$, using $\mathrm{FE}$ model for $F_{T}=2.16 \mathrm{MN}, k=700$, $v=0.3$, and $E=30 \mathrm{MPa}$. 


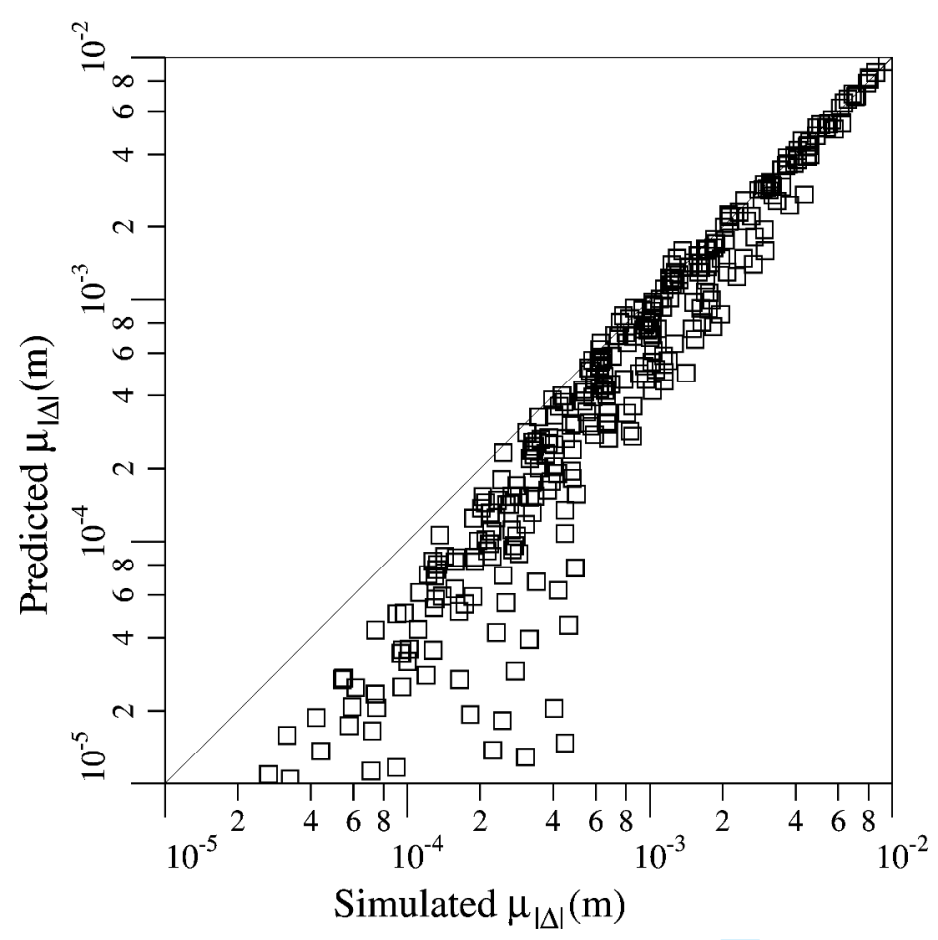

Figure 4. Predicted, obtained via eq. (5), versus simulated mean absolute differential settlement, $\mu_{|\Delta|}$, for all cases listed in Table 1 


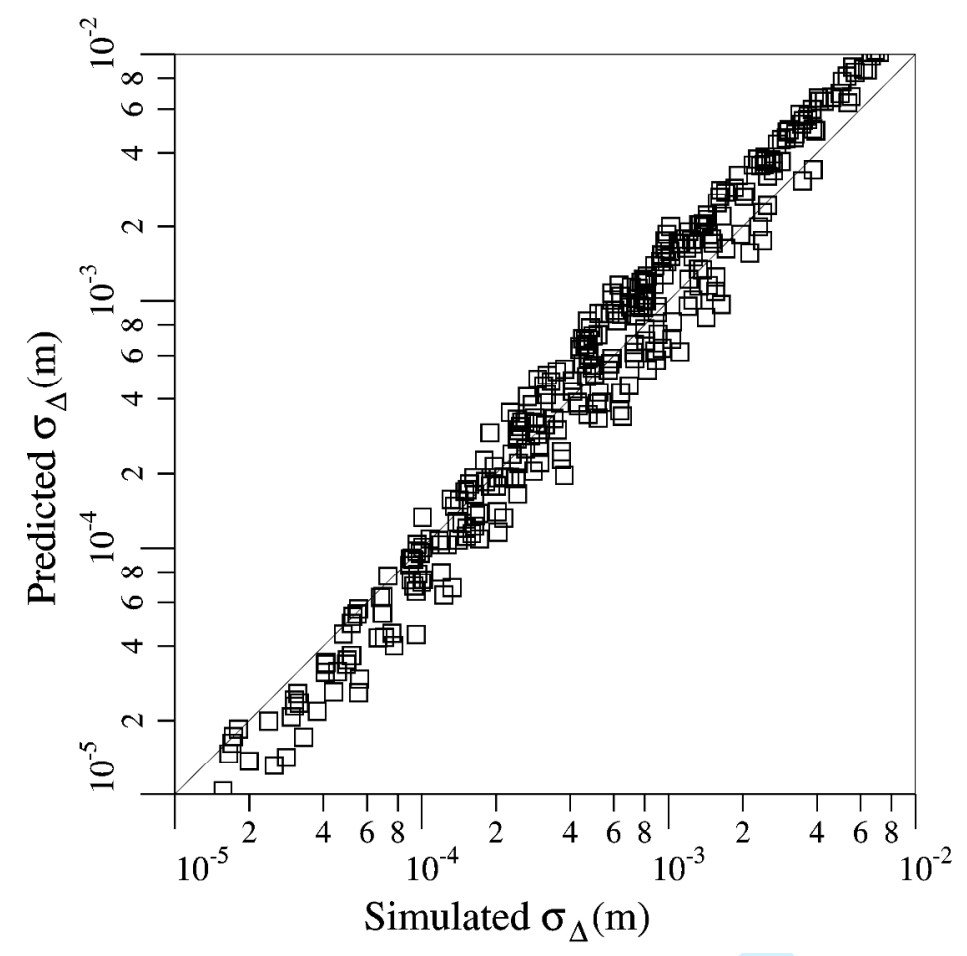

Figure 5. Predicted, obtained via eq. (24), versus simulated standard deviation differential settlement, $\sigma_{\Delta}$, for all cases listed in Table 1. 


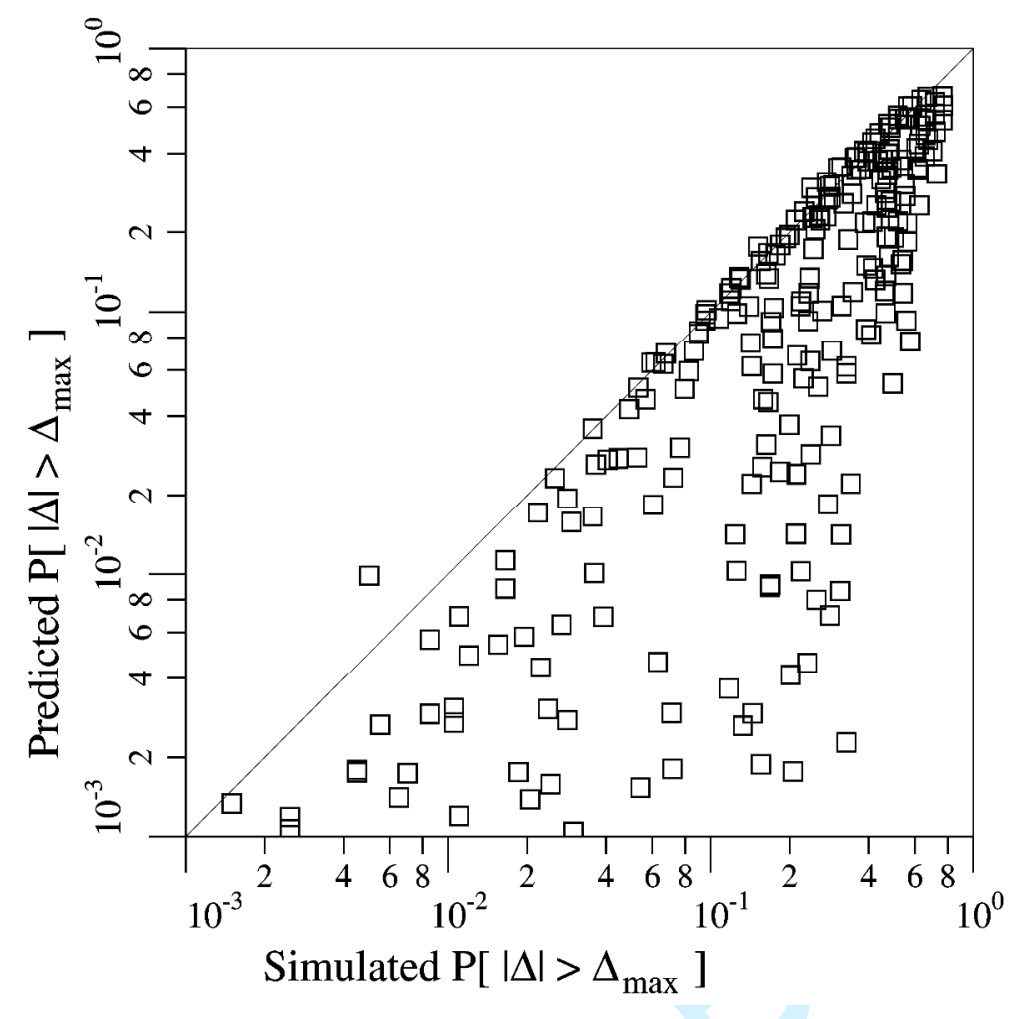

Figure 6. Predicted, via eq. (27), versus simulated $\mathrm{P}\left[|\Delta|>\Delta_{\max }\right]$ for all cases listed in Table 1. 


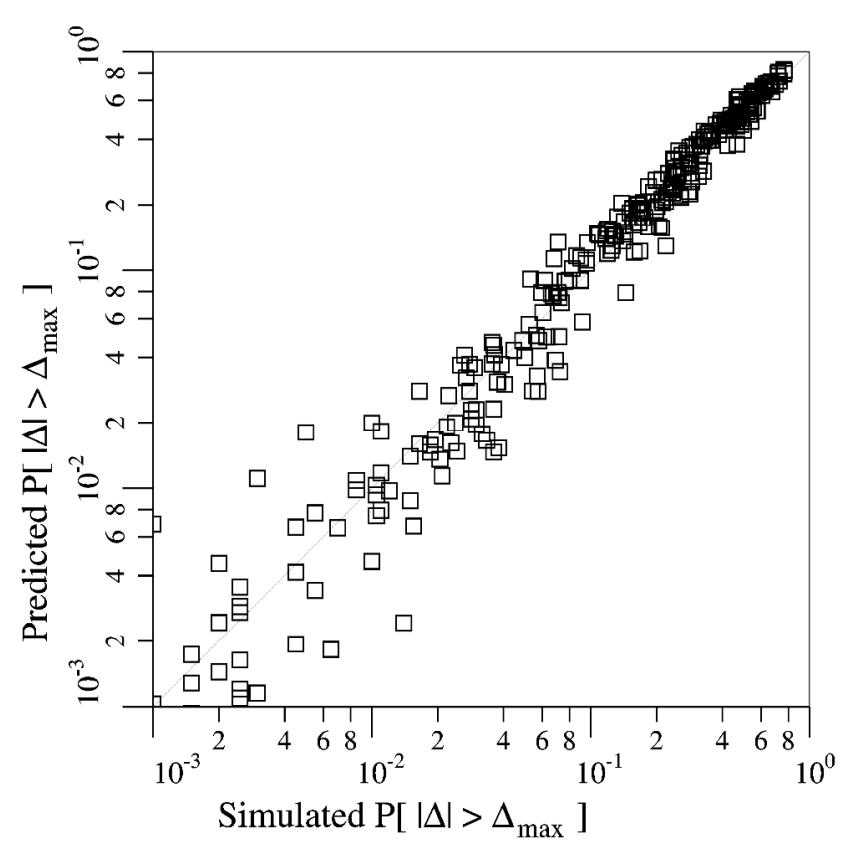

Figure 7. Predicted, obtained via eq. (27), versus simulated $\mathrm{P}\left[|\Delta|>\Delta_{\max }\right]$, adjusted by replacing $\eta$ with $-0.5 \eta$ for $H<3 \mathrm{~m}$, with zero for $3 \leq H \leq 6 \mathrm{~m}$, and with $0.5 \eta$ for $H>6 \mathrm{~m}$ 

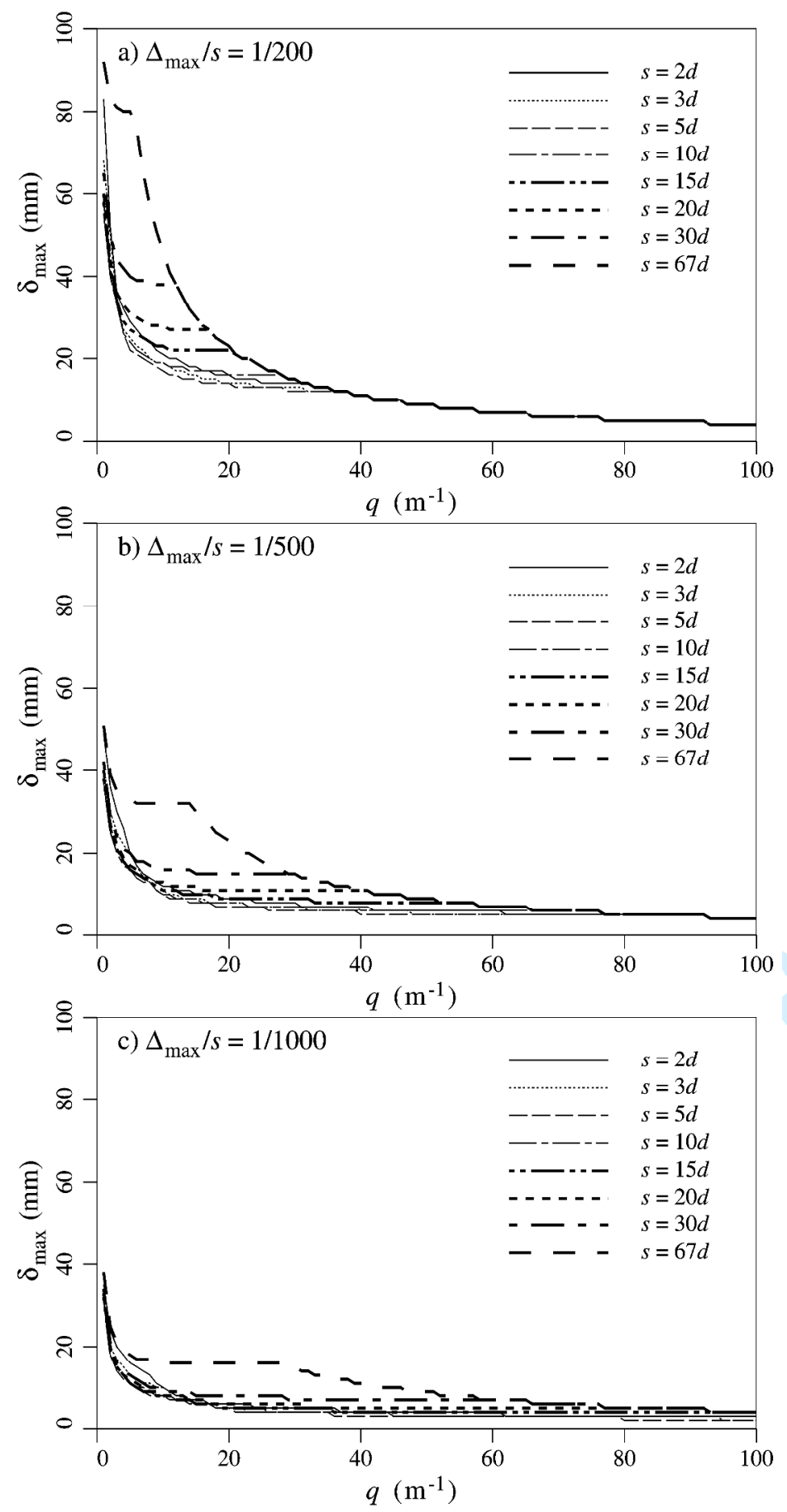

Figure 8. Recommended design $\delta_{\max }$ versus $q$ for various pile spacings, $s$, and maximum acceptable gradient, $\Delta_{\max } / s=$ a) $1 / 200$, b) $1 / 500$, and c) $1 / 1000$. 
Table 1. Input parameters used in the validation of theory

\begin{tabular}{cc}
\hline Parameters & Values Considered \\
\hline$d$ & $0.3 \mathrm{~m}$ \\
\hline$E_{p}$ & $21000 \mathrm{MPa}$ \\
\hline$F_{T}$ & $1.46,2.16,3.16 \mathrm{MN}$ \\
\hline$\mu_{E}$ & $30 \mathrm{MPa}$ \\
\hline$v_{E}$ & $0.1,0.3,0.5$ \\
\hline Poisson's ratio, $v$ & 0.3 \\
\hline$\theta_{\ln E}$ & $0.01,0.1,0.5,1.0,5.0,10.0 \mathrm{~m}$ \\
\hline$s$ & $2 d, 3 d, 5 d, 10 d, 15 d, 20 d, 30 d$ \\
\hline$n_{s i m}$ & 2000 \\
\hline$B$ & $2 \mathrm{~m}$ \\
\hline$C$ & $2 H$ \\
\hline
\end{tabular}

Table 2. Input parameters used in Figure 8

\begin{tabular}{cc}
\hline Parameters & Values Considered \\
\hline$d$ & $0.3 \mathrm{~m}$ \\
\hline$E_{p}$ & $21000 \mathrm{MPa}$ \\
\hline$\mu_{E}$ & $30 \mathrm{MPa}$ \\
\hline$v_{E}$ & $0.1,0.3,0.5$ \\
\hline$\varphi_{g s}$ & 1.0 \\
\hline$\theta_{\ln E} s$ & $2 d$ to $67 d$ \\
\hline$B$ & $2 \mathrm{~m}$ \\
\hline$C$ & $2 H$ \\
\hline$\Delta_{\max } / s$ & $1 / 200,1 / 500,1 / 1000$ \\
\hline $\operatorname{target} \beta$ & 2.9 \\
\hline
\end{tabular}

